http://doi.org/10.35784/iapgos.931

\title{
MODEL PREDICTIVE CONTROL APPLICATION IN THE ENERGY SAVING TECHNOLOGY OF BASIC OXYGEN FURNACE
}

\author{
Oleksandr Stepanets, Yurii Mariiash
}

National Technical University of Ukraine "Igor Sikorsky Kyiv Polytechnic Institute”, Department of Automation of heat-and-power engineering processes, Kyiv, Ukraine

Abstract. The fulfilment of the condition for the simultaneous achievement of the desired chemical composition and temperature of the metal is ensured by controlling the oxygen consumption and the position of the oxygen impeller lance. The method for solving Model Predictive Control with quadratic functionality in the presence of constraints is given. Implementation of the described solutions will contribute to increasing the proportion of scrap and reducing the melting period without changing of technological process.

Keywords: model predictive control, basic oxygen furnace, optimal control, energy saving

\section{ZASTOSOWANIE MODELU STEROWANIA PREDYKCYJNEGO W ENERGOOSZCZEDDNEJ TECHNOLOGII PROSTEGO PIECA TLENOWEGO}

\begin{abstract}
Streszczenie. Spetnienie warunku jednoczesnego osiagnięcia pożadanego składu chemicznego i temperatury metalu jest zapewnione poprzez kontrole zużycia tlenu i położenia palnika tlenowego. Zaprezentowano metodę rozwiazania Modelu Sterowania Predykcyjnego z funkcjonalnościa kwadratowa w obecności ograniczeń. Wdrożenie opisanego rozwiazania przyczyni się do zwiększenia udziału złomu i skrócenia czasu topnienia bez zmiany procesu technologicznego.
\end{abstract}

Słowa kluczowe: model sterowania predykcyjnego, prosty piec tlenowy, optymalna kontrola, oszczędność energii

\section{Introduction}

Steel production is a complex process that requires the use of a complex of technological, energy and transport equipment, each of which requires appropriate automation. Today, carbon steel is mainly produced using blast furnace route where basic oxygen furnace (BOF) basic oxygen furnace has an important role [8]

The intensification and complication of technological processes, increasing the capacity of units and increasing the quality requirements of finished products make it impossible to manage the units without improving the structure of automatic control systems. Despite the significant popularity of the classical theory of control with PID-controllers [9], the main part of the research conducted today is the use of process optimization [1] and improvement of predictive models [2].

Automation of the BOF involves obtaining high quality steel, which is possible while achieving the desired chemical composition and metal temperature $[2,6]$. This condition is ensured by controlling the flow of oxygen and the position of the lance of the oxygen converter, so solving the problem of controlling the purge of the converter bath is the main task. That is why the task of implementing modern control methods in the conditions of stochasticity, non-stationarity and limitations of technological processes is an urgent problem today [10]. Classical approaches are designed for the thermal mode, which determines the software trajectory of the control effects. Today, more and more research is focused on steelmaking raw materials and energy optimization [1]. One modern advanced control method is control theory using predictive models, such as Model Predictive Control (MPC). Model Predictive Control is an optimal control strategy based on numerical optimization [7].

\section{The aim and objectives of the study}

The purpose of the work is to develop an automatic control system for basic oxygen furnace-smelting, which would provide the specified quality indicators in conditions of unsteadiness of the rate of decompression and perturbations associated with changes in oxygen consumption for purging and introduction of loose. To achieve the objective, the following tasks were formulated:

to study the dynamic properties of the process of changing the rate of decarbonization of metal;

obtain a predictive model of the degree of carbon oxidation to the carbon dioxide of the oxygen-converter process;

to solve the problem of MPC-control with quadratic functional in the presence of restrictions.

\section{Mathematical model of oxygen converter process}

The transient process of changing the rate of decarburization from changing the distance of the lance to the level of a quiet bath is described by the transfer function (1) of the form [3]:

$$
W_{v_{c}}(s)=\frac{k_{v_{c}}}{T_{v_{c}} s+1}
$$

where $k_{v_{c}}[t /(h \cdot m)]$ - the transmission coefficient through the channel distance of lance to the level of a quiet bath - the rate of decarburization; $T_{v_{c}}[\mathrm{~s}]$ - time constant.

The time constant (2) is non-stationary and also depends on the melting period. It can be described functions [3]:

$$
T_{v_{c}}=\left\{\begin{array}{l}
1.143+4.446 \tau-0.484 \tau^{2}, 1 \text { period } \\
11.267,2 \text { period } \\
11.267-4.446(\tau-16)+0.484(\tau-16)^{2}, 3 \text { period }
\end{array}\right.
$$

where $\tau[\mathrm{min}]$ - purging time.

Changing the rate of decarburization leads to a change in the degree of carbon oxidation to carbon dioxide in the converter cavity. This process is also described by the first-order transfer function (3) of the form [3]:

$$
W_{\gamma_{\mathrm{CO}_{2}}}(s)=\frac{k_{\gamma_{\mathrm{CO}_{2}}}}{T_{\gamma_{\mathrm{CO}_{2}}} s+1}
$$

where $k_{\gamma_{\mathrm{CO}_{2}}}\left[\%_{\mathrm{CO}_{2}} \cdot \min \cdot t^{-1}\right]$ is the transmission rate through the channel of the speed of carbonation - the degree of carbon oxidation to $\mathrm{CO}_{2} ;-$ it is time. According to the results of experimental studies [5], the transmission rate of the channel is the carbonation rate - the degree of carbon oxidation to $\mathrm{CO}_{2}$ is determined from the balance equation of the purge flow rate $k_{\gamma_{\mathrm{CO}_{2}}}=3.33 \%_{\mathrm{CO}_{2}} \cdot \min \cdot t^{-1}$

The two links are connected in series (4) and the transfer function of the system in which the input value of the lance distance to the level of a quiet bath and the output - the degree of carbon oxidation to $\mathrm{CO}_{2}$ :

$$
W_{v_{c}}(s)=\frac{k_{v_{c}} \cdot k_{\gamma_{\mathrm{CO}_{2}}}}{\left(T_{v_{c}} s+1\right)\left(T_{\gamma_{\mathrm{CO}_{2}}} s+1\right)}=\frac{k_{\gamma_{\mathrm{CO}_{2}}}^{\mathrm{H}}}{\left(T_{v_{c}} s+1\right)\left(T_{\gamma_{\mathrm{CO}_{2}}} s+1\right)}
$$


where $k_{v_{c}}\left[\%_{\mathrm{CO}_{2}} \cdot m^{-1}\right]$ - the transmission coefficient through the channel distance of lance to the level of a quiet bath - the degree of carbon oxidation to $\mathrm{CO}_{2}$.

The system on the channel "position of the swing flap vacuum in the caisson" has a transfer function (5):

$$
W_{v}(s)=\frac{0,55}{5 s+1} e^{-s}
$$

where $W_{v}(s)$ - a transfer function on the channel "position of the swing flap - vacuum in the caisson".

\section{MPC controller design and control system modelling}

The design of a quadratic-functional MPC controller with constraints was performed using the Matlab MPC Designer package [11]. The design of the MPC controller (Fig. 1) used the mathematical model of the oxygen converter process, which is described in section 2 .

The predictive model (6) of the oxygen converter process for the second purge period of the oxygen converter process is obtained:

$$
\begin{aligned}
& x_{i+1}=A x_{i}+B u_{i}, \\
& y_{i}=C x_{i}, \\
& i=k+j, j=0,1,2 \ldots,
\end{aligned}
$$

where $k$ - tact number, $x_{i} \in E^{n}-$ the state of the object, $y_{i} \in E^{r}$ - measurements, $u_{i} \in E^{m}-$ control action,

$$
\begin{aligned}
A & =\left(\begin{array}{ccccc}
-1.613 & 0 & 0 & 0 & 0 \\
0 & -0.0887 & 0 & 0 & 0 \\
9.677 & 0 & -0.2924 & 0 & 0 \\
0 & 0 & 0 & -0.2 & 0 \\
0 & 0.3426 & 0.00146 & 0 & -0.466
\end{array}\right), \\
B & =\left(\begin{array}{ccc}
1 & 0 & 0 \\
0 & 1 & 0 \\
0 & 0 & 0 \\
0 & 0 & 1 \\
0 & 0 & 0
\end{array}\right), \\
C & =\left(\begin{array}{ccccc}
9.677 & 0 & 0 & 0 & 0 \\
0 & 0 & 0 & 0 & 1.522 \\
0 & 0 & 0 & 0.11 & 0
\end{array}\right)
\end{aligned}
$$

The dynamic properties of the actuators was introduced into the MPC-controller as the constraints on the input values (Fig. 2).

The quality of control is characterized by a linear-quadratic functional (7):

$$
\begin{aligned}
& J_{k}=J_{k}(\bar{y}, \bar{u})= \\
& =\sum_{j=1}^{P}\left[\left(y_{k+j}-r_{k+j}\right)^{T} R_{k+j}\left(y_{k+j}-r_{k+j}\right)+u_{k+j-1}^{T} Q_{k+j} u_{k+j-1}\right]
\end{aligned}
$$

where $R_{k+j}$ and $Q_{k+j}$ - positively defined symmetric matrices.

Auxiliary vectors (8):

$$
\begin{aligned}
& \bar{y}=\left(\begin{array}{lllll}
y_{k+1} & y_{k+2} & \ldots & y_{k+P}
\end{array}\right)^{T} \in E^{r P} \\
& \bar{u}=\left(\begin{array}{llll}
u_{k} & u_{k+1} & \ldots & u_{k+P-1}
\end{array}\right)^{T} \in E^{m P}
\end{aligned}
$$

Given that the movement of the system (6) on the clock is only determined, then. The problem of optimization (9) with respect to the functional (7) can be formulated:

$$
J_{k}(\bar{u}) \rightarrow \min _{u \in E^{m P}}
$$

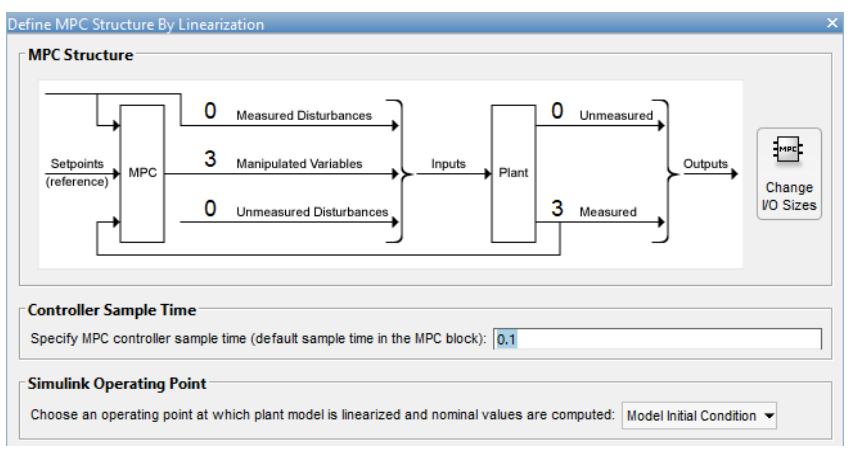

Fig. 1. Description of the structure of the MPC controller

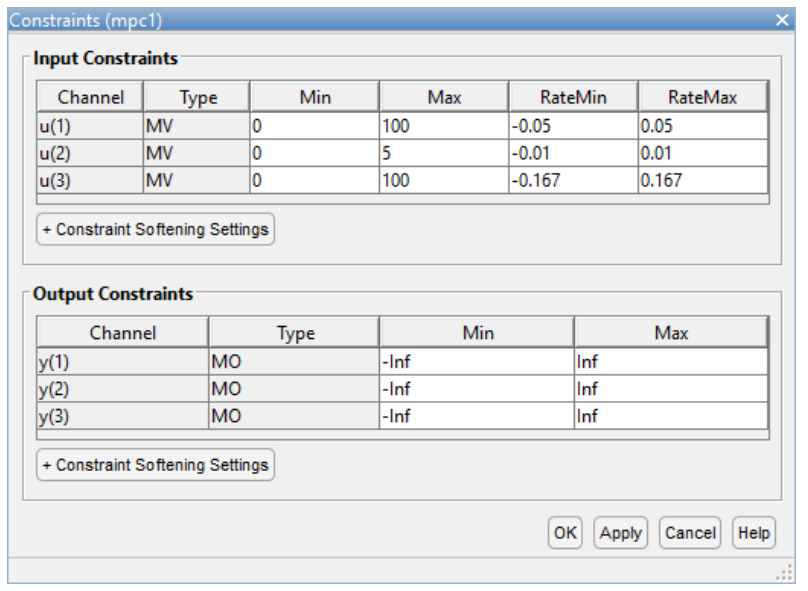

Fig. 2. Constraints to input values introduced in the MPC controller

The solution to problem (9) found, the functional (7) presented in the form (10):

$$
\begin{aligned}
& J_{k}=J_{k}(\bar{u})=(\bar{y}-\bar{r})^{T} R(\bar{y}-\bar{r})+\bar{u} Q \bar{u} \\
& y_{k+1}=C x_{k+1}=C A x_{k}+C B u_{k} \\
& y_{k+2}=C x_{k+2}=C A x_{k+1}+C B u_{k+1}=C A^{2} x_{k}+C A B u_{k}+C B u_{k+1} \\
& \text { e.t.c. } y_{k+P}=C x_{k+P}=C A^{P} x_{k}+C A^{P-1} B u_{k}+C B u_{k+1} \\
& \Rightarrow \bar{y}=L x_{k}+M \bar{u}, \text { where }
\end{aligned}
$$$$
L=\left(\begin{array}{l}
C A \\
C A^{2} \\
\cdots \cdots \\
C A^{P}
\end{array}\right) \quad \mathrm{M}=\left(\begin{array}{cccc}
C B & 0 & \cdots & 0 \\
C A B & C B & \cdots & 0 \\
\cdots & \ldots & \ldots & \\
C A^{P-1} B & C A^{P-2} B & \cdots & C B
\end{array}\right) \Rightarrow
$$

$J_{k}=J_{k}(\bar{u})=\left(L x_{k}+M \bar{u}-\bar{r}\right)^{T} R\left(L x_{k}+M \bar{u}-\bar{r}\right)+\bar{u} Q \bar{u}$

$\frac{\partial J_{k}}{\partial \bar{u}}=\frac{\partial}{\partial \bar{u}}\left[\left(L x_{k}+M \bar{u}-\bar{r}\right)^{T} R\left(L x_{k}+M \bar{u}-\bar{r}\right)+\bar{u} Q \bar{u}\right]=0$

$\frac{\partial J_{k}}{\partial \bar{u}}=M^{T} R\left(L x_{k}+M \bar{u}-\bar{r}\right)+Q \bar{u}=0$

$\Rightarrow \bar{u}^{*}=\bar{K} x_{k}+\bar{T} \bar{r}$

$$
\bar{K}=-\left(M^{T} R M+Q\right)^{-1} M^{T} R L, \bar{T}=\left(M^{T} R M+Q\right)^{-1} M^{T} R
$$

Matrix search algorithm:

1. Having matrices $A, B, C$ and forecast horizon $P$ to form matrices $L$ and $M$.

2. Using the input data in the form of matrices $R$ and $Q$ calculate additional matrices $\bar{K}$ and $\bar{T}$ from (10).

3. Select the upper blocks in size $m^{*} n$ and $m * r$ according to the matrices $\bar{K}$ and $\bar{T}$. 
According to the MPC strategy, the behaviour of the system is predicted and the resulting structure is optimized to find the optimal control of the oxygen converter. The obtained optimal control is applied at the current step, after which the forecast horizon shifts and the described sequence of actions is repeated [4]. The approach takes into account the constraints imposed on both control variables and control variables.

The simulation procedure was performed in the Matlab Simulink environment. An algorithm for solving the equations ode23s (stiff / mod. Rosenbrock) was chosen with variable-step change. The absolute and relative accuracy of the calculations is 0.0001 .

For a control system of oxygen consumption, a perturbation of a task of $15 \mathrm{~m}^{3} / \mathrm{min}$ (Fig. 3) relative to the nominal value of oxygen consumption is typical during purging. The obtained system quality indicators are shown in Table 1 .
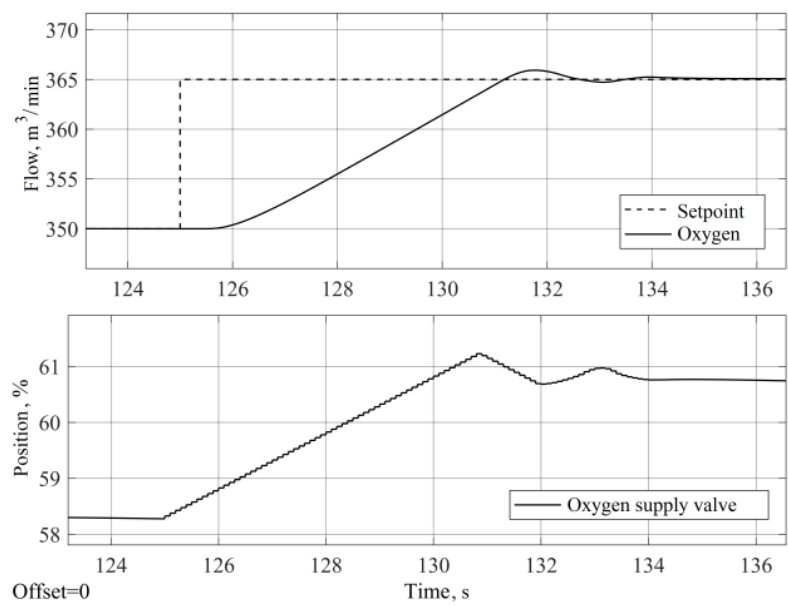

Fig. 3. Oxygen purge control system overflow position of oxygen supply valve - oxygen flow

Table 1. Quality indicators of SAR oxygen consumption

\begin{tabular}{|c|c|}
\hline Quality indicators & Value \\
\hline Static error & 0 \\
\hline Dynamic Error & 0.067 \\
\hline Adjustment time & $8 \mathrm{~s}$ \\
\hline The attenuation index & 0.95 \\
\hline Overshoot & $6.67 \%$ \\
\hline
\end{tabular}

For the control system of $\mathrm{CO}_{2}$ content, the main task is the problem of stabilization (Fig. 5) in the event of disturbances: changes in the flow rate of oxygen, change in the rate of decarburization, introduction of bulk, etc. Transitions through the perturbation-output channel are shown in Fig. 4. The obtained system quality indicators are shown in Table 2.
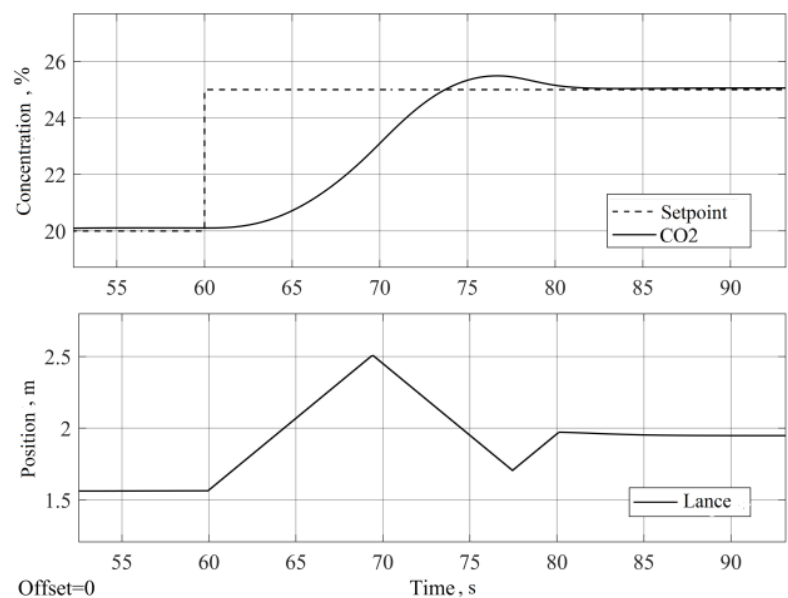

Fig. 4. Intermittent process of control system in the second period of purging through channel position of lance-CO2 content in flue gases
Table 2. Quality indicators of SAR of disturbances $\mathrm{CO}_{2}$ content

\begin{tabular}{|c|c|}
\hline Quality indicators & Value \\
\hline Static error & $0 \%$ \\
\hline Dynamic Error & 0.1 \\
\hline Adjustment time & $18 \mathrm{~s}$ \\
\hline The attenuation index & 1 \\
\hline Overshoot & $10 \%$ \\
\hline
\end{tabular}

Transitions through the disturbances for perturbation-output channel are shown in Fig. 5. The obtained system quality indicators are shown in Table 3.
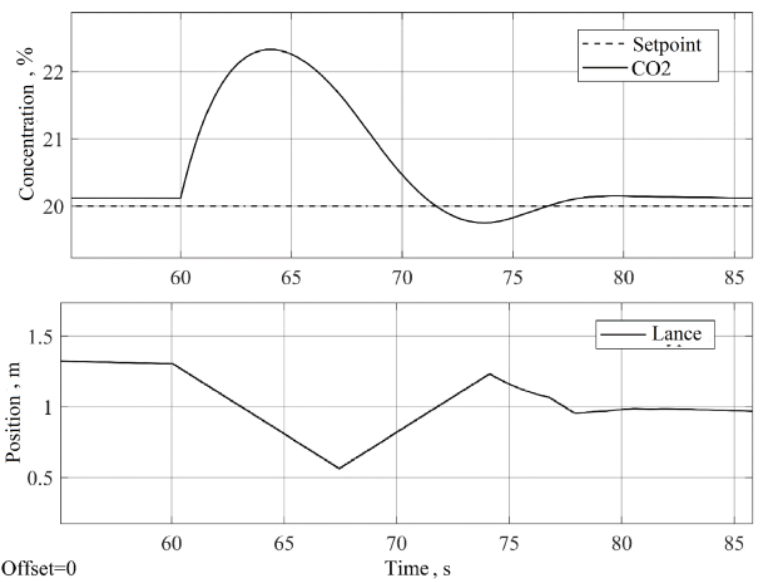

Fig. 5. Interrupting the process of the control system in the second period of purging through the channel change in the rate of decarburization - $\mathrm{CO} 2$ content in the flue gases

Table 3. Quality indicators of $\mathrm{SAR} \mathrm{CO}_{2}$ content

\begin{tabular}{|c|c|}
\hline Quality indicators & Value \\
\hline Static error & $0,1 \%$ \\
\hline Dynamic Error & 2,25 \\
\hline Adjustment time & $16 \mathrm{~s}$ \\
\hline The attenuation index & 0.92 \\
\hline Overshoot & $13.3 \%$ \\
\hline
\end{tabular}

To discharge the converter gases, a small (6-50 Pa) vacuum should be maintained in the caisson above the converter. Adjustment of pressure in a caisson is carried out by influence on a rotary damper in a gas-purifying tube. For the perturbation control system there is a converter gas recovery system. The transients of the system of automatic control of the vacuum on the channel vacuum-output are shown in Fig. 6, obtained system quality indicators are shown in Table 4.
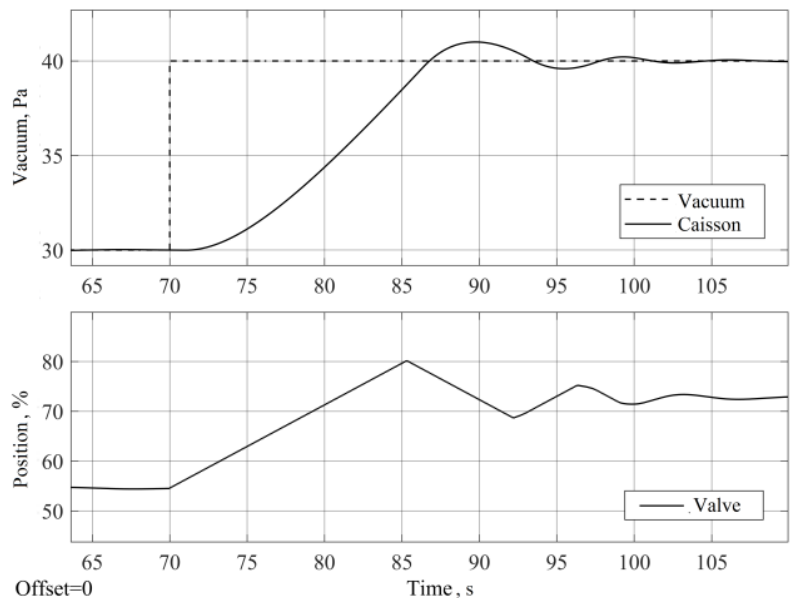

Fig. 6. Intersection process of the automatic control system on the vacuum channel by the gas-vacuum system in the caisson 
Table 4. Quality indicators of SAR vacuum in the caisson

\begin{tabular}{|c|c|}
\hline Quality indicators & Value \\
\hline Static error & 0 \\
\hline Dynamic Error & 0.09 \\
\hline Adjustment time & $27 \mathrm{~s}$ \\
\hline The attenuation index & 0.91 \\
\hline Overshoot & $9 \%$ \\
\hline
\end{tabular}

Transitions through the disturbances of the vacuum channel are shown in Fig. 7. The obtained system quality indicators are shown in Table 5.

Table 5. Quality indicators of SAR the disturbances of vacuum in the caisson

\begin{tabular}{|c|c|}
\hline Quality indicators & Value \\
\hline Static error & 0 \\
\hline Dynamic Error & $0.52 \mathrm{~Pa}$ \\
\hline Adjustment time & $18 \mathrm{~s}$ \\
\hline The attenuation index & 0.8 \\
\hline Overshoot & $0 \%$ \\
\hline
\end{tabular}

The simulation of oxygen transients during purging for a 160ton converter in the second purging period using an oxygen flow control algorithm aimed at ensuring the reliability of the
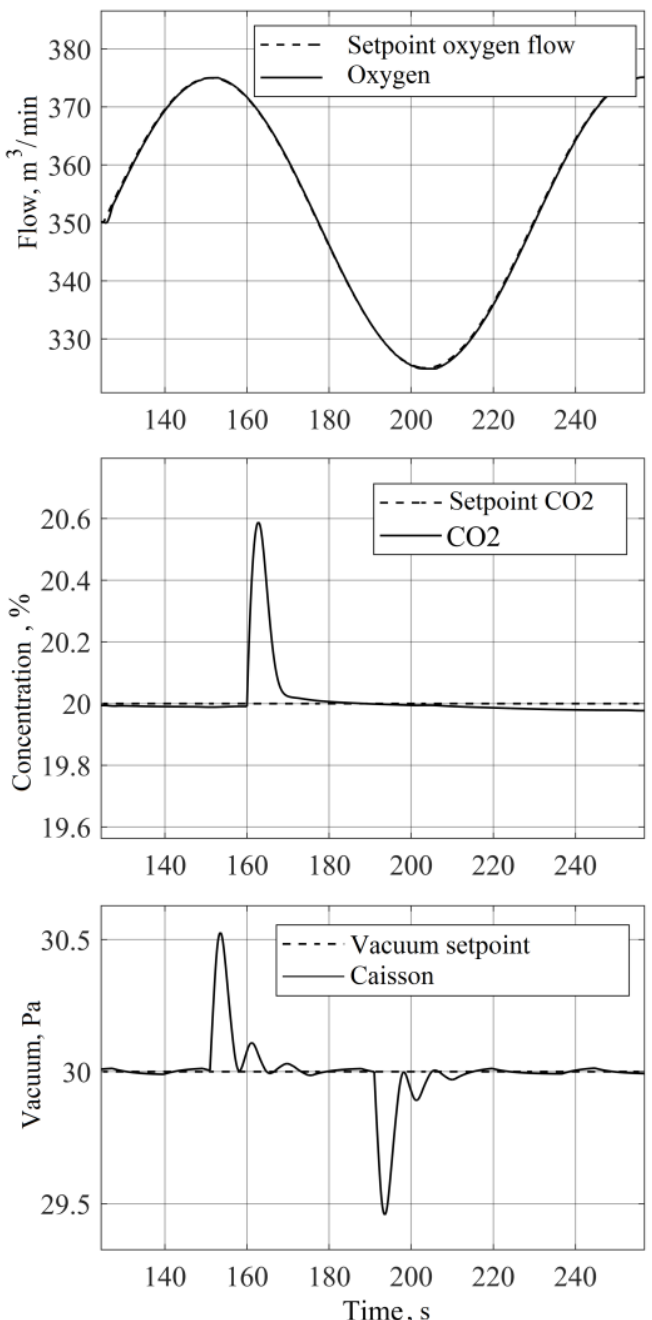

equipment and adjusting the position of the lance by the energysaving technology of combustion of $\mathrm{CO}$ to $\mathrm{CO}_{2}$ (Fig. 8). The obtained transients of the automatic control system of the basic oxygen furnace process using the MPC-strategy provide the requirements to the quality of the system.
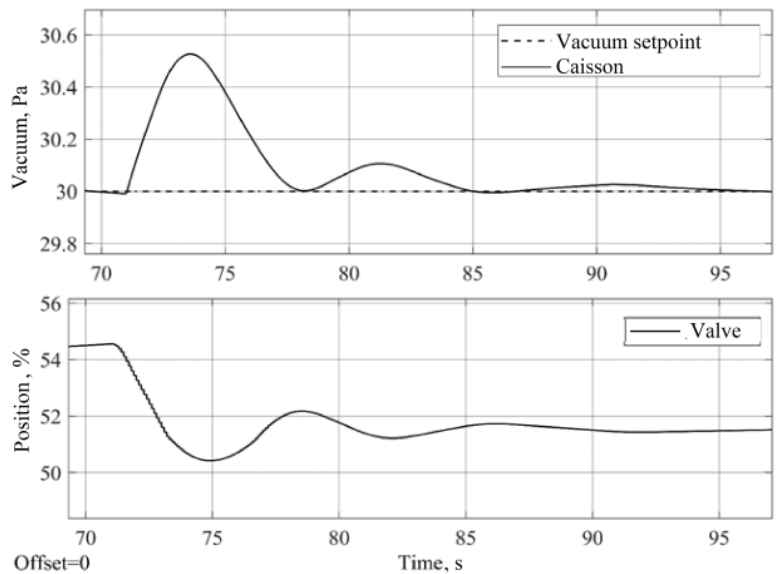

Fig. 7. Intersection process of the automatic control system on the vacuum channel by the gas-vacuum system in the caisson
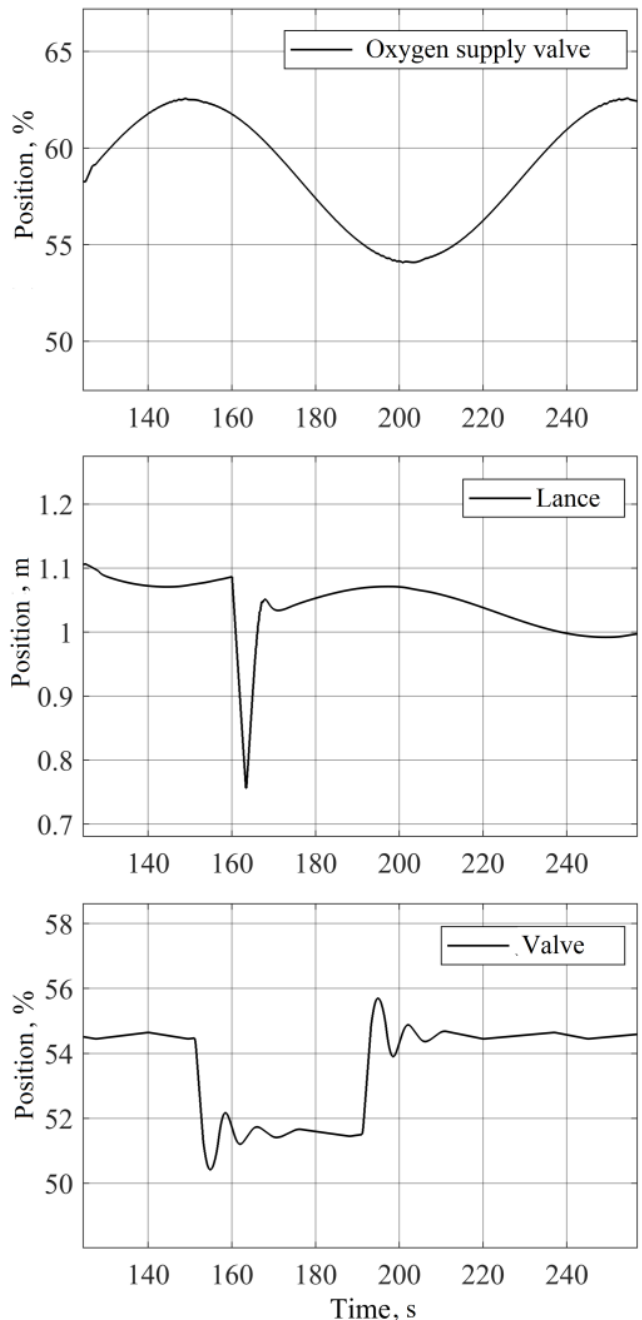

Fig. 8. Front processes of the automatic control system for oxygen converter melting during the second purge period 


\section{Conclusions}

An advanced process control of the refining and heating processes of the metal with reliable blast mode during the purge of the converter bath is described. The using of Model predictive control approach with taking into account the set requirements for quality of operation and provide high operations reliability is proposed.

It is known that at a certain chemical composition of iron, the thermal regime of the process depends on the rate of decarburization, the degree of combustion of $\mathrm{CO}$ to $\mathrm{CO}_{2}$ and the amount of iron oxides in the slag, which, in turn, depend on the distance of the lance to the level of a quiet bath. Adjustment of the lance position is carried out according to the economic regime, based on the increased degree of combustion of $\mathrm{CO}$ to $\mathrm{CO}_{2}$ in the converter cavity. The non-stationary of the melting processes is shown and explained. It makes the use of classical control methods irrational.

It is recommended to use the MPC strategy to solve those processes synchronization problem under physical and technical constraints. The approach minimizes the functionality that characterizes the quality of the adjustment process in real time. The predicted behaviour of a dynamic system will generally be different from its actual motion. Math models of processes are built. The decarburization process is represented as non-stationary first-order inertial transfer function, the gain and time constant of which depends on the melting period and the purge duration. The change in the degree of supplementation of $\mathrm{CO}$ to $\mathrm{CO}_{2}$ is also described by the such model type. The non-stationary oscillatory link describes the system in which the input value of the lance distance to the level of a quiet bath and the initial - the degree of carbon oxidation to $\mathrm{CO}_{2}$.

The behaviour of the system is predicted by MPC and the resulting structure is optimized to find the optimal control of the oxygen converter process. The approach takes into account the

Ph.D. Oleksandr Stepanets
e-mail: stepanets.av@ gmail.com
Associate professor of Department of Automation of
heat-and-power engineering processes of National
Technical University of Ukraine "Igor Sikorsky Kyiv
Polytechnic Institute".
Engages in the practical automation of complex
objects; Industrial Internet of Things; adaptive control
systems, model predictive control, fuzzy logic.
Responsible for the scientific direction of the
department.
http://orcid.org/0000-0003-4444-0705

constraints imposed on both control variables and control variables.

In order to work in real time, it is necessary that the solution of the optimization problem is carried out fairly quickly. The proposed approach was modeled in dynamics in the corresponding software environment. The simulation results show the achievement of the required quality indicators.

\section{References}

[1] Backman J., et al.: Methods and Tools of Improving Steel Manufacturing Processes: Current State and Future Methods. International Federation of Automatic Control PapersOnLine 52(13)/2019, 1174-1179 [http://doi.org/10.1016/j.ifacol.2019.11.355].

[2] Bogushevskiy V.S., et al.: System for the BOF Process Control. The Advanced Science Open Access Journal 5/2013, 23-27.

[3] Bogushevskiy V.S., Zuboka C.M.: Mathematical modeling of the converter process by energy-saving technology. Technological complexes 2/2013, 32-38.

[4] Camacho E.F., Bordons A.: Model Predictive Control. 2nd ed, Springer-Verlag London 2007.

[5] Cherneha D.F., et al.: Fundamentals of metallurgical production of metals and alloys. High School, Kyiv 2006

[6] Ghosh S., et al.: BOF process dynamics. Mineral Processing and Extractive Metallurgy 128(1)/2018, 1-17 [http://doi.org/10.1080/25726641.2018.1544331].

[7] Kouvaritakis B., Cannon M.: Model Predictive Control Classical, Robust and Stochastic. Springer-Verlag, London 2016.

[8] Ruuska J., et al.: Mass-balance Based Multivariate Modelling of Basic Oxygen Furnace Used in Steel Industry. International Federation of Automatic Control PapersOnLine 50(1)/2017. [http://doi.org/10.1016/j.ifacol.2017.08.2065]

[9] Stepanets O., Mariiash Y.: Analysis of Influence of Technical Features of a PID - controller Implementation on The Dynamics of Automated Control System. Eastern-European Journal of Enterprise Technologies 3(2)/2018, 60-69 [http://doi.org/10.15587/1729-4061.2018.132229].

[10] Zhang J.: Optimal Control Problem of Converter Steelmaking Production Process Based on Operation Optimization Method. Discrete Dynamics in Nature and Society 2015, Article ID 483674 [http://doi.org/10.1155/2015/483674].

[11] MathWorks. Design Controller Using MPC Designer. http://www.mathworks.com/help/mpc/gs/introduction.html?ue (available 5.09. 2018)

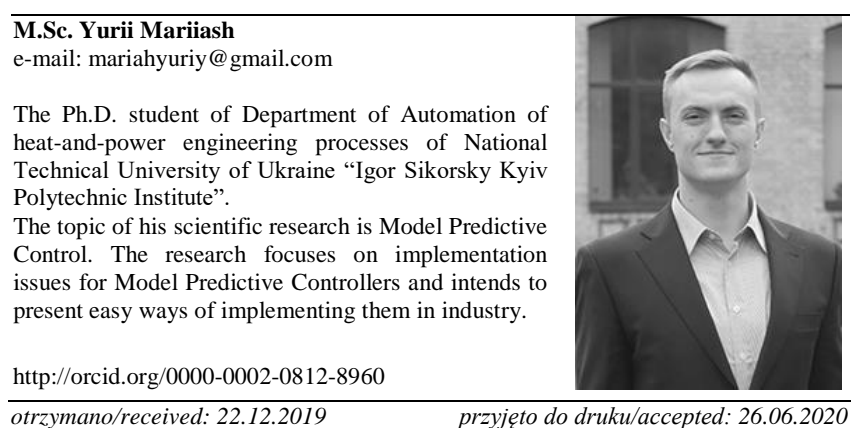

e-mail: mariahyuriy@gmail.com

The Ph.D. student of Department of Automation of heat-and-power engineering processes of National Technicat University of Ukraine "Igor Sikorsky Kyiv Polytechnic Institute". otrzymano/received: 22.12.2019 